\title{
Saúde na linha de fronteira Brasil-Uruguai: pactos e protagonismos dos atores locais ${ }^{1}$
}

\author{
Helenara Silveira Fagundes ${ }^{1}$ \\ https://orcid.org/0000-0003-2033-6276 \\ Ineiva Terezinha Kreutz ${ }^{1,3}$ \\ https://orcid.org/0000-0003-1976-9197
}

\author{
Vera Maria Ribeiro Nogueira ${ }^{1,2}$ \\ https://orcid.org/0000-0003-4158-1510 \\ Daniela Castamann ${ }^{1,4}$ \\ https://orcid.org/0000-0002-2812-2531
}

\author{
${ }^{1}$ Universidade Federal de Santa Catarina, Centro Socioeconômico, Programa de Pós-Graduação em Serviço Social, Florianópolis, SC, \\ Brasil (UFSC) \\ ${ }^{2}$ Universidade Católica de Pelotas, Centro de Ciências Sociais e Tecnológicas, Programa de Pós-Graduação em Política Social e Direitos \\ Humanos, Pelotas, RS, Brasil (UCPel) \\ ${ }^{3}$ Universidade Estadual do Oeste do Paraná, Centro de Ciências Sociais Aplicadas, Curso de Serviço Social, Toledo, PR, Brasil \\ (UNIOESTE) \\ ${ }^{4}$ Universidade Estadual do Paraná, Centro de Ciências Sociais Aplicadas, curso de Serviço Social, Apucarana, PR, Brasil (UNESPAR)
}

\section{Saúde na linha de fronteira Brasil-Uruguai: pactos e protagonismos dos atores locais}

Resumo: $\mathrm{O}$ texto analisa a relação entre os pactos e protocolos transfronteiriços na área da saúde e a atuação dos atores políticos na faixa de fronteira em dois pares de cidades-gêmeas entre Brasil e Uruguai. O objetivo foi resgatar o papel dos gestores e seu protagonismo, visando à atenção à saúde no plano local, considerando os atos binacionais. Foram entrevistados os gestores do sistema local de saúde. Dentre os resultados, destacam-se a dificuldade na materialização dos acordos binacionais e a consequente não ampliação dos direitos decorrentes do protagonismo dos sujeitos políticos locais. Não estão consolidados modelos de gestão cooperativa transfronteiriça, o que exige competência para articular consensos mínimos sobre pontos polêmicos, quando a perspectiva de gestão é democrática e universalista. Palavras-chave: Cooperação em saúde. Saúde em fronteiras. Política de saúde. Atores políticos. Gestão transfronteiriça em saúde.

\section{Health on the Brazil-Uruguay border: pacts and protagonism of local actors}

Abstract: This article analyzes the relationship between cross-border pacts and protocols in the area of health and the performance of political actors in two sets of twin cities that are on the Brazil-Uruguay border. The study aims to understand the role of the public health care managers and their leadership in providing services at the local level, considering binational acts. The managers of the local health care system were interviewed and among the results are the difficulties in the local materialization of the binational agreements, and the consequent stagnation in providing access to rights related to health, due to lack of leadership of the local political actors. Crossborder cooperative management models are not consolidated, which requires competence to obtain minimum consensus on controversial points when the management perspective is democratic and universalistic.

Keywords: Cooperation in health. Health at borders. Health policy. Political actors. Cross-border health management.

Recebido em 02.10.2017. Aprovado em 08.02.2018. Revisado em 12.03.2018.

(C) O(s) Autor(es). 2018 Acesso Aberto Esta obra está licenciada sob os termos da Licença Creative Commons Atribuição-NãoComercial 4.0 Internacional (https://creativecommons.org/licenses/by-nc/4.0/deed.pt_BR), que permite copiar, distribuir e reproduzir em qualquer meio, bem como adaptar, transformar e criar a partir deste material, desde que para fins não comerciais e que você forneça o devido crédito aos autores e a fonte, insira um link para a Licença Creative Commons e indique se mudanças foram feitas. 


\section{Introdução}

Este texto apresenta parte dos resultados de um estudo ${ }^{2}$ realizado na linha de fronteira entre o Brasil (BR), Argentina (AR), Paraguai (PY) e Uruguai (UY), com o objetivo de identificar os impasses e os condicionantes para a fruição do direito à saúde aos não nacionais, a partir de duas dimensões que sinalizam para o grau de institucionalidade das políticas de saúde ${ }^{3}$, ou seja, a jurídico-normativa e a técnico-operativa. A primeira dimensão refere-se aos acordos bilaterais existentes ${ }^{4}$, a segunda diz respeito à percepção dos gestores quanto a estes mesmos acordos, as dificuldades e possibilidades do sistema de saúde. Ou seja, como as inovações nos dispositivos jurídico-administrativos e relacionais, na linha de fronteira entre Brasil e Uruguai, incidem sobre a tríade desigualdade territorial em saúde, direito à saúde e acesso aos bens e serviços de saúde, com ênfase no papel protagônico desempenhado pelos atores políticos locais ${ }^{5}$. Este enfoque decorre dos resultados de pesquisas anteriores ${ }^{6}$ que constatavam a existência de instrumentos jurídico-administrativos relacionados, direta ou indiretamente, com a garantia do acesso aos bens e serviços de saúde nas fronteiras, abrangendo a população fronteiriça ${ }^{7}$ e os brasiguaios ${ }^{8}$. Todavia os entrevistados das cidades-gêmeas, nesses estudos, mencionavam a existência dos tratados e acordos bilaterais, sem, no entanto, informar detalhes, demonstrando um conhecimento superficial sobre tais dispositivos.

Outro aspecto que impacta nesta abordagem é o fato de a garantia da fruição do direito à saúde ser definida pelo tipo de articulação estabelecida entre Estado e sociedade civil ${ }^{9}$, no âmbito local. Essa garantia exige a operacionalização de políticas e programas que forneçam os bens e serviços para nacionais e não nacionais e pressupõe, para sua implementação, um nível de institucionalidade marcado pela capacidade pública de planejar e executar ações, tendo a perspectiva democrática como norte a ser seguido (DI GIOVANNI; NOGUEIRA, 2013). A responsabilidade de gestão, no poder local, impõe habilidade política e técnica para concretizar as proposições federais, transformando-as efetivamente em políticas públicas na sua correta acepção. Neste sentido, destacam-se a competência mínima de planificação, consolidada nos aparelhos de Estado, seja do ponto de vista técnico de gestão, seja do ponto de vista político e da estruturação republicana da ordem política vigente - coexistência e independência de poderes, vigência de direitos de cidadania e capacidade coletiva de formulação de agendas públicas - para o exercício pleno da cidadania e uma cultura política compatível com esta visão de direitos (DI GIOVANNI; NOGUEIRA, 2013).

Um terceiro aspecto incidente sobre essa garantia diz respeito ao protagonismo dos atores locais, seja os gestores, seja os profissionais, notadamente os designados na literatura como burocratas ao nível de rua (LIPSKY, 1980); ou seja, atores políticos e profissionais e que estão na ponta dos sistemas de proteção social e executam os programas concernentes a seu campo de ação, a partir de uma releitura destes. Um ponto em comum nas experiências analisadas em estudos anteriores (NOGUEIRA, 2011a, 2011b; AGUSTINI, 2008; AGUSTINI; NOGUEIRA, 2010; NOGUEIRA; FAGUNDES; PÉREZ, 2011) mostra que, quando positivas ou mesmo inovadoras, essas experiências são decorrentes da iniciativa de alguns gestores mais afinados com a garantia universal do acesso aos bens e serviços de saúde. No plano local, deparam-se com três situações singulares que, articuladas, orientam as decisões, os planos e a gestão dos sistemas de saúde: as necessidades em saúde, as diferenças dos sistemas de saúde e a localização fronteiriça. Deve-se recordar que esses atores políticos não têm competências legais similares nos dois países devido ao grau de descentralização de cada país.

Torna-se, assim, uma questão relevante verificar em que medida os dispositivos relacionais de ampliação de direitos são apreendidos e reconstituídos na implementação. Assim, este texto tem como objetivo resgatar o papel dos gestores e ex-gestores e o seu protagonismo visando à atenção à saúde aos não nacionais no plano local, considerando os atos binacionais entre Brasil e Uruguai. São abordados os resultados obtidos em dois pares de cidades-gêmeas - Santana do Livramento e Quaraí (Brasil) e Rivera e Artigas (Uruguai). Essa escolha deve-se à relevância desses municípios na história de cooperação binacional na fronteira Brasil e Uruguai. Nessas localidades, foram entrevistados os gestores e ex-gestores do setor saúde no período de julho a novembro de 2016. Os recortes das entrevistas transcritas neste texto são identificados como G1, G2, G3, G4 e G5. A apresentação dos resultados foi estruturada em três seções: a primeira é referente às particularidades da questão da saúde em espaços transfronteiriços; a segunda trata da relação entre política pública, fronteiras e atores políticos e a terceira identifica os acordos bilaterais na área da saúde e aborda o protagonismo dos gestores locais buscando a materialização ou não dos pactos, protocolos e acordos bilaterais.

\section{Particularidades da política de saúde em espaços transfronteiriços}

Pensar em política de saúde em espaços transfronteiriços impõe pensar no mundo da saúde que, no entender de Conill e Fernandez (2015, p. 11), pode ocorrer a partir de “[...] um diálogo entre o mundo das ideias 
(das formulações e teorias), o mundo dos registros (que abarca todo tipo de documento e informação registrada em algum suporte) e o mundo real (onde se estabelecem as relações e o convívio entre as redes sociais e os indivíduos)". É nesse mundo real que se decide sobre a maior ou menor garantia da fruição do direito à saúde, definida pelo tipo de relação estabelecida entre Estado e sociedade civil e, no âmbito local, demandam a operacionalização de políticas e programas que forneçam os bens e serviços previstos para nacionais e não nacionais. Os direitos são garantidos via políticas públicas e pressupõe, para sua implementação, um nível de institucionalidade marcado pela capacidade pública de planejar e executar ações, tendo a perspectiva democrática como norte a ser seguido (DI GIOVANNI; NOGUEIRA, 2013). O âmbito municipal é o espaço privilegiado na implementação das decisões programáticas formalizadas em políticas, situando-se como um ente político-administrativo no qual as condições acima devem ser resguardadas.

Em faixas de fronteira, verifica-se que os sistemas locais de saúde devem ser observados a partir da dimensão organizativa de prestação de serviços e ações de saúde oferecidas e também da demanda de uma população que transita por ambos os lados da fronteira. Esse trânsito impõe uma situação delicada enfrentada pelos gestores, da qual se origina, em inúmeras situações, a exigência de cooperação entre os sistemas locais de saúde dos países limítrofes. Entretanto, muitas vezes, a cooperação é bastante assimétrica, influenciada, entre outros fatores, pela postura ético-política dos gestores, reduzindo ou mesmo anulando a possibilidade de atenção aos usuários do sistema, seja brasileiros residindo do outro lado da fronteira internacional, seja não nacionais residentes do outro lado da linha fronteiriça.

Ao se refletir sobre os sistemas locais de saúde, duas dimensões relativas à fruição dos direitos sociais devem ser levadas em conta: os dispositivos relacionais entre a dimensão jurídico-normativa e a implementação de políticas com ênfase no papel desempenhado pelos atores políticos locais - dimensão técnico-operativa. Em fronteiras internacionais, a dimensão jurídico-normativa incorpora não unicamente a legislação nacional, mas igualmente os pactos assinados pelos países e internalizados nos ordenamentos jurídicos nacionais.

No Brasil, o tema cooperação em faixas de fronteiras aparece, inicialmente, nos estudos de Gallo, Costa e Moraes (2004), Giovanella (2007), Giovanella e Guimarães (2005). Esses estudos vêm na esteira da preocupação do governo nacional, a partir de 2002, com a integração desses espaços, favorecendo a institucionalização e a coesão social do Mercado Comum do Sul (MERCOSUL).

Neste texto, a cooperação transfronteiriça se refere unicamente aos possíveis intercâmbios e colaborações entre sistemas locais de saúde, na linha da fronteira internacional, como a forma, por excelência, de garantir o acesso aos bens e serviços de saúde aos não nacionais, por meio da prestação de ações e serviços de saúde.

Como uma questão transversal ao tema abordado situam-se as desigualdades territoriais em saúde, ocorridas ao longo da linha da fronteira, as quais são incorporadas ao debate sobre o direito à saúde e implementadas, via execução de políticas de saúde, com o objetivo de reduzir essas desigualdades. As desigualdades territoriais decorrem, em um mesmo território, de atenção desigual em saúde, não se garantindo direitos igualitários entre os habitantes de um mesmo território contíguo. Entende-se que a simples existência de uma rede de serviços instalada não é suficiente para a erradicação das desigualdades territoriais em saúde. Para isso, requerem-se estratégias que incluam outros aspectos intrínsecos que conformariam a atenção integral à saúde, como a questão do meio ambiente, saneamento básico, entre outras.

Parte-se do pressuposto de que as políticas públicas são resultantes da configuração dos atores políticos, de recursos e regras, no sentido de produzir bens ou serviços

O longo percurso da construção e consolidação de um acordo assinala uma questão-chave para a implementação dos pactos bilaterais: a renovação das gestões municipais e nacionais com alterações nos quadros funcionais, não se mantendo o necessário seguimento desse processo no sentido de construir e consolidar institucionalidades mais sólidas no âmbito da proteção à saúde. para resolver necessidades coletivas, sob a responsabilidade ou coordenação do Estado (GIRAUD; WARIN, 2008). As análises sobre as políticas públicas levam em conta as transformações recentes da ação estatal, evidentes no uso crescente de instrumentos despolitizados (nível jurídico e administrativo), na imposição do saber nos processos decisionais e reguladores (agências 
reguladoras e novas formas de regulação estatal), mudanças de escala no controle democrático (nacional/ local), com montagem de vias infra e supranacionais e, ainda, a crescente judicialização no encaminhamento das decisões e operação da ação pública (BORRAZ; GUIRAUDON, 2010).

Essa afirmação se sustenta, teoricamente, na linha de debates acerca da implementação das políticas, em autores que marcam a relevância dessa etapa do ciclo das políticas públicas, a qual pode reverter a finalidade precípua do programa proposto por força dos acordos binacionais ou multilaterais que influenciam os processos decisórios em nível municipal (NOGUEIRA, 2011a, 2011b; LOTTA, 2012; COSTA; BRONZO, 2012; SENNA et al., 2013; FARIA, 2012). Essa situação, no Brasil, tanto pode levar a dinâmicas inclusivas como acentuar processos de exclusão da população transfronteiriça devido à autonomia municipal na gestão do sistema de saúde e à forma de pactuação entre os níveis de governo. Entende-se, portanto, que o local também é lugar de fabricação de ação pública, conforme assinalam Borraz e Guiraudon (2010).

\section{Política pública, fronteiras e atores políticos}

Serão utilizadas referências relativas à política social e política pública, complementares entre si, tratando a política de saúde com traços históricos determinantes, decorrentes de situações problemáticas e constitutivas de desigualdades.

A primeira formulação marca a relação entre política social e estrutura social, influenciando-se mutuamente e operando sobre um eixo igualdade/desigualdade. Importa essa indicação na medida em que as instituições - no caso os sistemas locais de saúde - girando em torno do eixo desigualdade/igualdade em saúde têm seu papel (normas, rotinas, regras) e lugares definidos pelo ordenamento jurídico nacional e, em caso de fronteira, também pelos acordos e pactos internacionais. Essas normativas, ao serem transpostas para o plano local sob a forma técnico-operativa, constroem novas racionalidades ao cumprirem, ou não, as determinações derivadas do poder nacional. "[...] independentemente de Itamarati, do Ministério da Saúde, nós vamos fazendo a nossa saúde de fronteira, sim, nem sempre de acordo com as normativas nacionais." (G4, 2016). Essa posição sinaliza para a discricionariedade dos gestores e dos demais agentes relacionados com a operacionalização das políticas. No caso de cooperação transfronteiriça, as maiores desigualdades são determinadas pela situação de classe social e, paradoxalmente, pela cidadania.

A segunda formulação apreende a política de saúde como política pública, não sendo, entretanto, unicamente uma intervenção do Estado em uma situação entendida como crítica. Essa é considerada a forma contemporânea de exercício do poder nas sociedades democráticas, decorrente da interação entre o Estado e a sociedade, "[...] entendida aqui num sentido amplo, que inclui as relações sociais travadas também no campo da economia". (DI GIOVANNI, 2009, p. 4). Afirma-se ser nessa interação que se definem as situações sociais consideradas como factíveis de serem incorporadas à agenda pública, bem como, as formas, os conteúdos, os meios, os sentidos e as modalidades de intervenção estatal. Ainda de acordo com o mesmo autor, essa formulação depende de condições prévias, ou seja, alguns aspectos delineadores das modernas democracias: "[...] destaca-se uma capacidade mínima de planejamento no interior das instituições estatais aspectos técnicos e políticos; a vigência de uma ordem política garantindo os direitos de cidadania e atores políticos competentes na formulação das agendas públicas”. (DI GIOVANNI, 2009, p. 1).

Esses aspectos são essenciais para averiguar a implementação de programas e iniciativas jurídicoadministrativas em diferentes níveis de ação pública. Cada nível dispõe de competências diversas, e as mudanças de escala - do global ao local, passando pelo nacional - têm um impacto na formulação da ação pública e na determinação do grau de universalidade garantido.

[...] a gente precisa discutir porque se tu pensar em Direitos Humanos e não entender que Saúde é direito humano, direito à vida, não tem nem como discutir direito humano. É nesse sentido que eu penso saúde pública e por isso a luta não é minha, do meu bairro, da minha casa [...] é uma luta permanente por um sistema público melhor para todos os habitantes nesse sentido. (G1, 2016).

[...] não consigo concordar com o atendimento ao estrangeiro porque tiram o lugar de um brasileiro, $o$ nosso atendimento aqui já é um pouco limitado, tudo por agendamento, por marcação e liberação de consultas do Estado, que já é demorado. (G3, 2016).

Ou seja, a descentralização provoca uma fragmentação da proposta programática inicial, pois novas decisões são tomadas no momento da implementação e alteram o estatuto de cidadania em relação à garantia de direitos, em face do poder dos atores políticos locais. Um depoimento expressa essa autonomia: "Ah si... 
nuestra consigna siempre fue primero hacer y luego discutir porque en temas de salud no puedes... tenes que inventar... y si estamos de acuerdo a nivel local...lo hicimos". (G2, 2016).

Outro marco significativo a ser considerado é a própria concepção de fronteira, territorialidade e seus desdobramentos nos sistemas municipais de saúde e na vida cotidiana local. Os territórios ou as multiterritorialidades ${ }^{10}$ de fronteiras internacionais são lugares com particularidades que vão além dos marcos regulatórios dos Estados nacionais. As fronteiras, para serem entendidas em suas complexas determinações, exigem uma visão de totalidade, superando a visão tradicional, de limite territorial e área de segmentação política e social. "[...] las poblaciones de Uruguay y de Brasil se confunden, entonces para eso nosotros tenemos que hablar más o menos un lenguaje común. El idioma no nos separa y el puente tampoco nos separa." (G5, 2016).

Como espaços limites, no âmbito jurídico formal, e espaços de vivências integrativas, no âmbito cotidiano, distanciam-se de outros espaços nacionais. A linha de fronteira ${ }^{11}$ assinala um "[...] espaço de interação, uma paisagem específica, com espaço social transitivo, composto por diferenças oriundas da presença do limite internacional, e por fluxos e interações transfronteiriças, cuja territorialização mais evoluída é a das cidades-gêmeas." (BRASIL, 2005, p. 21). Para Giovanella e Guimarães (2005), a intensificação dos intercâmbios entre as nações provoca na região de fronteira, uma situação caracterizada pela falta de certezas em relação a questões de integração e sua concretização, associada à convivência cotidiana, às diferenças de idioma, cultura, sistemas políticos, monetários, de seguridade e proteção social.

Cada ciudad fue buscando la forma de ayudarse complementarse y de intercambiar servicios: en el caso de Rivera y Livramento, como por ejemplo, ellos a veces tienen problemas con los gineceos, entonces ficam sin plantão de ginecologistas y o hospital de Rivera hace el plantón y nós no temos resonador magnético, entonces la troca de servicios es plantan por resonancia magnética. (G2, 2016).

Esse aspecto incide diretamente nas estruturas relacionais entre as instituições e grupos sociais, e os atores políticos locais (gestores e profissionais) atuam mediando e articulando as possibilidades locais para inclusão, ou não, de não nacionais nos sistemas de proteção social no âmbito da saúde.

\section{Ações de cooperação e os gestores locais}

Atualmente um aspecto relevante na construção dos sistemas de saúde, principalmente em áreas fronteiriças, relaciona-se às ações de cooperação técnica e tecnológica, aprimorando a atenção à saúde. Nessa linha destaca-se a longa trajetória de cooperação recíproca entre o Brasil e o Uruguai em áreas fronteiriças, iniciada em 1928, por meio do Convênio Relativo à Luta contra as Enfermidades Venereosifiliticas na Fronteira Comum aos dois Países, o qual ainda está em vigor. Posteriormente, em 1969, firmam um novo acordo, visando a melhoria das condições sanitárias na região de fronteira. A partir de 2005 acentua-se a cooperação entre os dois países, na esteira da expansão do MERCOSUL.

A evidência dessa cooperação recíproca é expressa em acordos, memorandos e ajustes em vigor, estabelecidos entre o Brasil e o Uruguai, conforme o Quadro 1.

Observa-se nos documentos consulares que muitos não se relacionam à situação de fronteira, mas optou-se por apresentá-los porque indiretamente têm incidência naquele espaço, que também é nacional, especialmente os de cooperação técnica e tecnológica. Destaca-se que a tramitação de um tratado, acordo, ajuste ou memorando entre os países é competência dos órgãos federais, com exceção da Argentina, que formaliza em sua Constituição a possibilidade de os entes subnacionais estabelecerem acordos. Devem, ainda, ser internalizados ao ordenamento jurídico de cada um dos países, ou seja, aprovados pelos respectivos parlamentos e sancionados pela Presidência.

Possivelmente pelo fato de essa tramitação ser realizada distante da fronteira, os gestores nem sempre têm o conhecimento sobre os acordos, mencionando unicamente o Acordo de Permissão de Residência, Estudo e Trabalho a Nacionais Fronteiriços Brasileiros e Uruguaios, de 21 de agosto de 2002. Mesmo esta menção é pontuada de incertezas, uma vez que os relatos demonstram uma frágil apropriação do conteúdo dos acordos e memorandos. As incertezas são decorrentes, na perspectiva dos gestores, de entraves concernentes à regulamentação e tramitação desse acordo e a sua inserção no ordenamento jurídico dos países. Ressalta-se que um dos gestores possui um conhecimento maior sobre o teor do acordo e alguns detalhes de seu conteúdo e intencionalidade, e aponta o longo período de debates e reuniões que antecedeu o acordo, tendo participado de todo o processo de discussão. 


\section{Quadro 1 - Pactos bilaterais entre o Brasil e o Uruguai 2003-2011 ${ }^{12}$}

\begin{tabular}{|c|c|c|}
\hline DOCUMENTO & DATA & SÍNTESE \\
\hline $\begin{array}{l}\text { Memorando de Entendimento no Âmbito da } \\
\text { Troca de Experiência em Transplantes de Órgãos } \\
\text { e Tecidos. }\end{array}$ & $18 / 06 / 2003$ & $\begin{array}{l}\text { Objeto - Fortalecer o Programa de Cooperação Científica Brasil- } \\
\text { Uruguai, em relação à troca de experiência em Transplantes de } \\
\text { Órgãos e Tecidos. }\end{array}$ \\
\hline $\begin{array}{l}\text { Ajuste Complementar ao Acordo de Cooperação } \\
\text { Técnica, Científica e Tecnológica para Saúde na } \\
\text { Fronteira. }\end{array}$ & $31 / 07 / 2003$ & $\begin{array}{l}\text { Objeto - criação e implementação da Comissão Binacional Asses- } \\
\text { sora de Saúde na Fronteira Brasil-Uruguai. }\end{array}$ \\
\hline $\begin{array}{l}\text { Decreto } \mathrm{N}^{\circ} 5.105 \text {, de } 14 \text { de junho de } 2004 . \\
\text { Promulga o Acordo para Permissão de Residência, } \\
\text { Estudo e Trabalho a Nacionais Fronteiriços } \\
\text { Brasileiros e Uruguaios, de } 21 \text { de agosto de } 2002 .\end{array}$ & $14 / 06 / 2004$ & $\begin{array}{l}\text { Objeto - Permissão de Residência, Estudo e Trabalho, residentes } \\
\text { nas seguintes localidades fronteiriças: Chuí, Santa Vitória do Palmar, } \\
\text { Balneário do Hermenegildo e Barra do Chuí (BR) a Chuy, Barra de } \\
\text { Chuy e La Coronilla (UY); 2) Jaguarão (BR) a Rio Branco (UY); 3) } \\
\text { Aceguá (BR) a Aceguá (UY); 4) Santana do Livramento (BR) a } \\
\text { Rivera (UY); 5) Quaraí (BR) a Artigas (UY); 6) Barra do Quaraí } \\
\text { (BR) a Bella Unión (UY). }\end{array}$ \\
\hline $\begin{array}{l}\text { Ajuste Complementar - Projeto "Fortalecimento } \\
\text { Institucional das Assessorias Internacionais dos } \\
\text { Ministérios da Saúde do Brasil e do Uruguai”. }\end{array}$ & $22 / 11 / 2006$ & $\begin{array}{l}\text { Objeto - contribuir para o fortalecimento das Assessorias de Coo- } \\
\text { peração Internacional dos Ministérios da Saúde do Brasil e Uru- } \\
\text { guai, promovendo, dessa forma, o intercâmbio de informações e o } \\
\text { planejamento e desenvolvimento de ações conjuntas, na área da } \\
\text { saúde pública. }\end{array}$ \\
\hline $\begin{array}{l}\text { Ajuste Complementar ao Acordo para Permissão } \\
\text { de Residência, Estudo e Trabalho a Nacionais } \\
\text { Fronteiriços Brasileiros e Uruguaios, para } \\
\text { Prestação de Serviços de Saúde. }\end{array}$ & $28 / 11 / 2008$ & $\begin{array}{l}\text { Objeto - o acesso dos cidadãos fronteiriços aos serviços de saúde, } \\
\text { na região fronteiriça. São contemplados os serviços de caráter pre- } \\
\text { ventivo; serviços de diagnóstico; serviços clínicos, inclusive trata- } \\
\text { mento de caráter continuado; serviços cirúrgicos, inclusive trata- } \\
\text { mento de caráter continuado; internações clínicas e cirúrgicas; e } \\
\text { atenção de urgência e emergência. }\end{array}$ \\
\hline $\begin{array}{l}\text { Ajuste Complementar - Projeto “Apoio ao } \\
\text { Fortalecimento do Sistema Nacional de Sangue e } \\
\text { Hemoderivados do Uruguai”. }\end{array}$ & $25 / 05 / 2009$ & $\begin{array}{l}\text { Objeto - transferência de conhecimentos técnicos e da capacitação } \\
\text { de profissionais, com vistas a estabelecer as bases de um sistema } \\
\text { capaz de atender com segurança e qualidade a necessidade do país } \\
\text { em relação ao Sistema Nacional de Sangue e Hemoderivados. }\end{array}$ \\
\hline $\begin{array}{l}\text { Ajuste Complementar - Projeto "Fortalecimento } \\
\text { das Políticas de Enfrentamento à Epidemia de } \\
\text { DST/AIDS no Uruguai". }\end{array}$ & $25 / 09 / 2009$ & $\begin{array}{l}\text { Objeto - a finalidade de fortalecer a resposta do Uruguai ao HIV/ } \\
\text { AIDS, em termos de assistência, prevenção, direitos humanos, } \\
\text { sociedade civil e organizações das pessoas vivendo com HIV/AIDS. }\end{array}$ \\
\hline $\begin{array}{l}\text { Ajuste complementar - “Apoio Técnico para a } \\
\text { Expansão e Consolidação da Rede de Bancos de } \\
\text { Leite Humano do Uruguai”. }\end{array}$ & $13 / 12 / 2010$ & $\begin{array}{l}\text { Objeto - cooperação técnica para expansão e consolidação da Rede } \\
\text { de Banco de Leite Humano. }\end{array}$ \\
\hline Memorando de Entendimento na Área da Saúde & $30 / 05 / 2011$ & $\begin{array}{l}\text { Objeto - ampliar o desenvolvimento conjunto de projetos de coo- } \\
\text { peração técnica, principalmente em relação ao acesso aos medica- } \\
\text { mentos, atenção básica; redes integradas de serviços; capacidade } \\
\text { regulatória, recursos humanos e participação social. }\end{array}$ \\
\hline $\begin{array}{l}\text { Ajuste Complementar - Projeto "Apoio Ao } \\
\text { Fortalecimento do Sistema Nacional Integrado } \\
\text { de Saúde do Uruguai com Ênfase em Localidades } \\
\text { com Menos de Cinco Mil Habitantes". }\end{array}$ & $30 / 05 / 2011$ & $\begin{array}{l}\text { Objeto - a implementação do projeto "Apoio ao Fortalecimento } \\
\text { do Sistema Nacional Integrado de Saúde do Uruguai, com ênfase } \\
\text { em localidades com menos de cinco mil habitantes", cuja finalidade } \\
\text { é contribuir para o fortalecimento do sistema integrado de saúde. }\end{array}$ \\
\hline $\begin{array}{l}\text { Ajuste Complementar - Projeto "Consolidação } \\
\text { da capacidade Institucional do Ministério de } \\
\text { Saúde do Uruguai e Ampliação do Diálogo } \\
\text { Regulatório entre as Autoridades Sanitárias de } \\
\text { Brasil e Uruguai". }\end{array}$ & $30 / 05 / 2011$ & $\begin{array}{l}\text { Objeto - fortalecer a parceria técnica, qualificação e capacitação } \\
\text { institucional do Ministério da Saúde Pública do Uruguai na área da } \\
\text { vigilância sanitária. }\end{array}$ \\
\hline
\end{tabular}

Fonte: Brasil(2017). 
O longo percurso da construção e consolidação de um acordo assinala uma questão-chave para a implementação dos pactos bilaterais: a renovação das gestões municipais e nacionais com alterações nos quadros funcionais, não se mantendo o necessário seguimento desse processo no sentido de construir e consolidar institucionalidades mais sólidas no âmbito da proteção à saúde. Esse cenário implica o conhecimento parcial dos acordos e como consequência provoca dificuldade em sua implementação.

Outro limite em relação aos acordos assinalados pelos gestores dos dois países é sua essência normativa e pouco esclarecedora sobre aspectos administrativos e financeiros como, no caso brasileiro, a contratação de profissionais, pagamento de serviços e honorários, pagamento de Autorização de Internação Hospitalar (AIH), restrição ao exercício dos profissionais de saúde, entre outros. Em relação aos aspectos particulares da assistência à saúde, observa-se a mesma dificuldade, impossibilitando a referência e contrarreferência, emissão de receituários, alimentação do banco de dados do sistema de saúde, emissão de AIH. Do lado uruguaio, não se mencionam restrições quanto ao exercício profissional, entretanto, apontam-se dificuldades administrativas. Cabe destacar uma questão mencionada pelos entrevistados em relação à contratação de médicos uruguaios para prestação de serviços no Brasil, possível a partir de uma liminar da Justiça autorizando o exercício profissional, mesmo sem a revalidação do diploma no Brasil, conforme exigência do Ministério da Educação.

No hay libre tránsito de profesionales en la frontera, pero de hecho se da que cuando en una ciudad, por ejemplo, en el caso de Livramento hacen un llamado a concurso para ginecólogo y no hay nadie que se presente al lado brasilero. El juez la justicia brasilera hace una liminar y el profesional puede trabajar del otro lado sin haber este revalidado y que es lo que se está dando. (G2, 2016).

Esse processo foi iniciativa de um dos gestores de uma das cidades-gêmeas brasileiras, apoiando-se no Acordo para Permissão de Residência, Estudo e Trabalho a Nacionais Fronteiriços Brasileiros e Uruguaios, de 21 de agosto de 2002, e no Acordo sobre Residência para Nacionais dos Estados Partes do Mercado Comum do Mercosul-Mercosul, Bolívia e Chile, de 2002, que seguem vigentes.

Os demais acordos não foram mencionados, sinalizando o distanciamento entre a gestão do nível nacional e local. Não foram apontadas iniciativas de orientação de técnicos dos Ministérios, Estados e Departamentos, favorecendo a apreensão dos gestores da situação dos acordos e das possibilidades no sentido de propiciar o atendimento aos cidadãos fronteiriços. A percepção dos gestores da importância dos acordos para qualificar a ação municipal e favorecer o atendimento, em uma perspectiva universalista, considerando a especificidade das cidades-gêmeas, parece ser frágil, possivelmente por causa da lentidão desse processo. Ou seja, as formas de construção de dispositivos bilaterais e multilaterais, relatadas anteriormente, demandam um processo longo e centrado no alto escalão, com distintos entes nacionais envolvidos (Ministérios da Saúde, Relações Exteriores, entre outros). Além disso, alguns dispositivos permanecem longo tempo em tramitação no poder legislativo, aguardando aprovação para integrar a ordem normativa. Esses aspectos contribuem para o retardamento de seus resultados, e impacta, ainda, nesse processo a questão político-partidária, ou seja, o interesse da aprovação em casos de consensos do partido político ou vice-versa.

A inexistência de um trato único sobre a atenção aos não nacionais expressa a discricionariedade dos responsáveis pela saúde, fazendo com que cada gestor local atenda à demanda de acordo com sua perspectiva ético-política, a disponibilidade de recursos para prestação dos serviços e o interesse de grupos envolvidos com o setor saúde. Na medida em que há o conhecimento parcial dos acordos, a planificação dos sistemas de saúde exige que os gestores construam as suas próprias estratégias de respostas às demandas provenientes dos não nacionais e busquem uma aproximação com os congêneres do outro lado da fronteira. "En Uruguay es una política de salud nacional. El espacio lo tenemos que crear nosotros, porque el centralismo es igual en todos. Si no creamos el espacio nosotros y no hablamos nosotros, Montevideo no va a hablar.” (G2, 2016).

Segundo os relatos, as ações conjuntas (Brasil e Uruguai) se encontram nas áreas de vigilância sanitária e epidemiológica. As atividades referem-se ao controle de vetores e transmissores de doenças. Foram destacadas campanhas conjuntas de educação e prevenção como: redução de danos e prevenção ao uso de drogas, violência doméstica, violência e abuso sexual contra criança e adolescentes, temas transexuais, suicídios, acidentes de trânsito, saúde mental. Estas ações foram ressaltadas pelos gestores devido à abrangência e resultados alcançados. Destaca-se que as ações bilaterais acima mencionadas decorrem de iniciativas provenientes dos Comitês/Comissões de Fronteira ${ }^{13}$, nos quais participam gestores, profissionais de saúde e os cônsules dos dois países. Essas ações foram estabelecidas a partir de pactos informais, transitórios e pontuais entre os gestores, desfavorecendo, por esta razão, uma continuidade que poderia se encaminhar para relações paradiplomáticas, em longo prazo.

Um exemplo paradigmático desta situação de iniciativa dos gestores dos sistemas se encontra na troca de serviços, com base em pactos verbais e informais, não transitando para possibilidade de um acordo mais 
duradouro: “[...] plantão médico de profissionais uruguaios no hospital brasileiro por serviço de ressonância magnética brasileira". (G2, 2016).

Entretanto, embora se tenha reconhecimento da importância destas iniciativas, para qualificar os sistemas locais de saúde em um marco cooperativo, reaparece o vetor ético-político. Há relatos de que a maior ou menor intensidade do funcionamento e a regularidade das reuniões do Comitê e suas respectivas deliberações se encontram sujeitas: 1) ao contexto socioeconômico e político dos países; e 2) à mudança de atores locais, estaduais/provinciais e nacionais, que impacta a dinâmica dos Comitês, dependendo da postura e discricionariedade dos agentes locais.

Olha, eu participei por muito tempo, agora é uma pena que essas reuniões pararam ${ }^{14}$. Tem uma do Ministério da Integração Nacional, que funcionava e funcionava muito bem em nivel dos dois países, Uruguai e Brasil. E a gente fazia essas reuniões periódicas com os países e municípios fronteiriços. [...] Então, sempre vinha o pessoal do Ministério da Saúde e do Ministério da Saúde também do Uruguai e a gente discutia essas questões importantes de intercâmbio, de cooperação mútua, entre os dois países, tanto na área da saúde, mas também outras áreas, mas nós participávamos especificamente na área da saúde. (G1, 2016).

[...] depende muito das pessoas, da voluntá, de trabalho das pessoas e da cabeza política da necessidade de trabalhar de diferente forma em la frontera: no son todos los partidos (politicos) que tienen; ideologicamente abertura para trabalhar a fronteira [...]. Os partidos políticos ven a la frontera de diferente forma. En el caso nuestro, el Partido Nacional que es un partido conservador, este siempre fue cerrado al trabajo de frontera. (G2, 2016).

As reuniões mencionadas foram paulatinamente canceladas e, com relação a isso, um dos gestores entrevistados interpreta que, posteriormente à assinatura do acordo de 2002, "[...] ya no vimos tantas necesidades de laborar, de elaboración como estábamos, como tuvimos una época que nos reuníamos mensualmente con la gente, con la comunidad, viendo las necesidades"(G2, 2016).

Uma série de desafios de ordem estrutural e conjuntural é assinalada por todos os gestores entrevistados. As dificuldades de ordem estrutural são relacionadas à necessidade de regulamentação dos acordos, tanto na área contábil, de recursos humanos e intercâmbio institucional, como na atenção de média e alta complexidade. Entre tais dificuldades estão: a inexistência de processos contábeis para pagamento de honorários e serviços, entre os serviços públicos de saúde dos dois países; grande fluxo de pessoas por ser área de fronteira; e inexistência de um hospital binacional universitário. De ordem conjuntural, as principais dificuldades são: a não regulamentação dos serviços hospitalares; regulamentação para pagamento (internacional) de serviços em saúde prestados pelos profissionais; retorno das reuniões do Comitê de Fronteira; falta de profissionais de saúde e necessidade de se estabelecer processos de referência e contra referência entre os sistemas de saúde.

As dificuldades mencionadas repõem o debate sobre as políticas públicas e suas exigências formais, sendo uma delas a planificação dos serviços de saúde. Os gestores, apesar do discurso divergente sobre o atendimento aos não nacionais, expressam a preocupação com a qualificação do sistema local de saúde, apontando diversas iniciativas que têm contribuído para reduzir as desigualdades em saúde em plano territorial. Ou seja, têm competência técnica para formular metas precisas em relação à política local de saúde, além de reconhecerem o limite das decisões e pactos paradiplomáticos. A sugestão mais relevante consiste em promover o intercâmbio em todos os serviços de fronteiras, constituindo uma região sanitária como efetivamente é.

\section{Considerações finais}

O objetivo deste artigo foi apresentar os impasses e as condicionantes para a fruição do direito à saúde aos não nacionais na fronteira entre o Brasil e o Uruguai, numa perspectiva de indicar o grau de institucionalidade das políticas de saúde, a partir da normatização jurídica e técnico-operativa, resgatando o protagonismo dos gestores.

A base jurídico-normativa é uma ferramenta poderosa para equalizar a cidadania social, mas insuficiente, na maioria das vezes, para a materialização dos planos, programas e projetos, sem os quais a situação não se altera. Especialmente se levarmos em consideração a democracia de baixa intensidade da maioria dos países latino-americanos. Embora tais tratados sejam instrumentos valiosos para a ampliação do acesso aos bens e serviços de saúde, e os gestores se constituam como atores políticos relevantes na gestão dos sistemas locais, parece ocorrer um gap entre o marco legal e a sua materialização (NOGUEIRA, 2011a, 2011b), o que sugere um problema de gestão ou opção ético-política. No que se refere à cooperação, observa-se uma situação delicada enfrentada pelos gestores, na medida em há uma exigência de cooperação entre os sistemas locais de saúde, fundamentada nos acordos bilaterais, em nível nacional, sem a sua tradução para o sistema 
local. O que ocorre é uma cooperação bastante assimétrica, influenciada pela postura dos gestores, pela rede de serviços existentes e pela própria dinâmica, historicamente constituída, de cada fronteira.

O protagonismo dos gestores, com uma única exceção, se expressa na mediação e articulação das possibilidades locais para a inclusão dos não nacionais nos sistemas de proteção social no âmbito da saúde, porém, há muitos desafios a serem enfrentados. Entre eles, podemos apontar: a regulamentação dos acordos na ordem estrutural e a necessidade de se estabelecer uma planificação bilateral entre os sistemas locais de saúde, com o objetivo de qualificar o atendimento e garantir os direitos de cidadania. Conclui-se que a cooperação, a consolidação e o fortalecimento de ações na área da saúde pública, em territórios de fronteira, têm se revelado necessários, urgentes e desafiadores, decorrentes das particularidades sociais, políticas, econômicas e culturais locais.

\section{Referências}

AGUSTINI, J. A descentralização da política nacional de saúde e sua institucionalidade nos sistemas municipais na linha da fronteira MERCOSUL. 2008. 231 f. Dissertação (Mestrado em Serviço Social) - Programa de Pós-Graduação em Serviço Social, Universidade Federal de Santa Catarina, Florianópolis, 2008.

.; NOGUEIRA, V. M. R. A descentralização da política nacional de saúde nos sistemas municipais na linha da fronteira Mercosul. Serviço Social e Sociedade, São Paulo, n. 102, p. 222-243, abr./jun. 2010. Disponível em: <http://www.scielo.br/pdf/sssoc/ n102/a03n102.pdf>. Acesso em: 27 out. 2014.

ATOS Internacionais. Governo do Brasil, 07 maio 2012. Disponível em: <http://www.brasil.gov.br/governo/2012/05/atos-internacionais>. Acesso em: 12 jan. 2016.

BORRAZ, O.; GUIRAUDON, V. (Org.). Politiques publiques 2: changer la société. Paris: Presses des Sciences Po, 2010.

BRASIL. Lei n. ${ }^{\circ}$ 13.445, de 24 de maio de 2017. Institui a Lei da Migração. Diário Oficial da União, Brasília, DF, 25 maio 2017. Disponível em: <http://www.planalto.gov.br/ccivil_03/_ato2015-2018/2017/lei/L13445.htm>. Acesso em: 14 set. 2017.

. Ministério da Integração Nacional. Grupo de Trabalho Interfederativo de Integração Fronteiriça. Bases para uma proposta de desenvolvimento e integração da faixa de fronteira. Brasília: Ministério da Integração Regional, 2010. Disponível em: <http:// www.integracao.gov.br/documents/4085233/0/BasesFaixadeFronteira.pdf/4c044041-a3d9-4aac-b1fa-f187ca12a276 >.Acesso em: 14 ago. 2017.

. Secretaria de Programas Regionais. Programa de Desenvolvimento da Faixa de Fronteira. Proposta de reestruturação do programa de desenvolvimento da faixa de fronteira: bases para uma política integrada de desenvolvimento regional para a faixa de fronteira. Brasília: Ministério da Integração Regional, 2005. Disponível em: <http://www.retis.igeo.ufrj.br/wp-content/uploads/2005livro-PDFF.pdf>. Acesso em: 14 set. 2017.

Ministério da Saúde. Assessoria de Assuntos Internacionais em Saúde. Acordos Internacionais - Lista dos Instrumentos Internacionais na Área da Saúde. 2017. Disponível em: <http://portalms.saude.gov.br/assessoria-internacional/acordos-internacionais>. Acesso em: 14 ago. 2017.

COMISSÃO ECONÔMICA PARA A AMÉRICA LATINA E O CARIBE. Institucionalidad Social para América Latina y Caribe. 2016. Disponível em: <http://dds.cepal.org/bdips/index.php>. Acesso em: 20 fev. 2016.

CONILL, E. M.; FERNANDES, S. (Coord.). Documento base para construção do Observatório Iberoamericano de Politicas e Sistemas de Saúde. Brasília: OIAPSS, 2011. Disponível em: <http://www.oiapss.org/wp-content/uploads/2012/12/Documento-Baseportugu\%C3\%AAs.pdf >. Acesso em: 20 fev. 2016.

COSTA, B. L. D.; BRONZO, C. Intersetorialidade no enfrentamento da pobreza: o papel da implementação e da gestão. In: FARIA, C. A. P. de. (Org.). Implementação de políticas públicas: teoria e prática. Belo Horizonte: PUC Minas, 2012. p. 50-81.

DI GIOVANNI, G. As estruturas elementares das políticas públicas. Caderno de Pesquisa NEPP/UNICAMP, Campinas, n. 82, 2009.

.; NOGUEIRA, M. A. (Org.). Dicionário de políticas públicas. São Paulo: IMESP, Fundap, 2013. 2 v.

FARIA, C. A. P. de. (Org.). Implementação de políticas públicas: teoria e prática. Belo Horizonte: PUC Minas, 2012.

GAllo, E.; COSTA, L; MORAES, A. A Integração dos Sistemas de Saúde que Atendem a População Fronteiriça dos Países do MERCOSUL - SIS-MERCOSUL. In: __________ (Org.). Sistema Integrado de Saúde do Mercosul: SIS-MERCOSUL: uma agenda para a integração. Brasília: Organização Pan-Americana da Saúde, 2004. p. 41-53.

GIOVANELLA, L (Coord). Saúde nas fronteiras: estudo do acesso aos serviços de saúde nas cidades de fronteira com países do MERCOSUL. Rio de Janeiro: ENSP/Fiocruz, 2007.

.; GUIMARÃES, L. Processo de integração regional no MERCOSUL e as repercussões nos sistemas de saúde de cidades fronteiriças. In: CONGRESO INTERNACIONAL DEL CLAD SOBRE LA REFORMA DEL ESTADO Y DE LAADMINISTRACIÓN PÚBLICA, 10., 2005, Santiago. Anais... Santiago: CLAD, 2005. p. 18-21.

GIRAUD, O.; WARIN, P. (Org.). Politiques publiques et démocratie. Paris: La Découverte, PACTE, 2008.

HAESBAERT, R. Dos múltiplos territórios à multiterritorialidade. Porto Alegre, 2004. Disponível em: <http://www.ufrgs.br/petgea/ Artigo/rh.pdf >. Acesso em: 20 jan. 2017.

LIPSKY, M. Street-level bureaucracy: dilemmmas of the individual in public services. New York: Russell Sage Foundation, 1980. LOTTA, G. S. O papel das burocracias do nível de rua na implemetação de políticas públicas: entre o controle e a discricionariedade. In: 
FARIA, C. A. P. de. (Org.). Implementação de políticas públicas: teoria e prática. Belo Horizonte: PUC Minas, 2012. p. $20-49$. NOGUEIRA, V. M. R. (Coord.). Ampliando o direito à saúde: experiências de cooperação entre sistemas e serviços de saúde em linha de fronteira. Pelotas, 2011a. Relatório de Pesquisa.

. (Coord.). O direito à saúde na perspectiva da população residente na linha da fronteira MERCOSUL. Florianópolis, 2008. Relatório de Pesquisa.

. (Coord.). Fronteira MERCOSUL: um estudo sobre o direito à saúde. Florianópolis, 2005. Relatório de Pesquisa.

. (Coord.). A implementação do Programa SIS Fronteiras e do Pacto pela saúde - perspectivas para a ampliação do direito à saúde aos usuários estrangeiros na fronteira Arco Sul. Pelotas, 2011b. Relatório de Pesquisa.

. (Coord.). A institucionalidade dos sistemas locais de saúde na linha da fronteira MERCOSUL. Florianópolis, 2006. Relatório de Pesquisa.

. (Coord.). Pactos, protocolos e o protagonismo dos atores políticos locais: impasses e condicionantes para o acesso aos bens e serviços na linha de fronteira Arco Sul. Pelotas, 2017. Relatório de Pesquisa.

. (Coord.). Uma questão e duas temporalidades: direito à saúde na fronteira MERCOSUL -2003-2013. Pelotas, 2015. Relatório de Pesquisa.

. et al. Pactos, protocolos y el protagonismo de actores políticos locales: impases y condicionantes para el acceso a bienes y servicios de salud en la línea de frontera del arco sur. In: CONGRESO INTERNACIONAL EN GOBIERNO, ADMINISTRACIÓN Y POLÍTICAS PÚBLICAS. 8., 2017, Madri. Anais... Madrid: GIGAP, 2017.

.; FAGUNDES, H. S.; PÉREZ, R. G. Experiências de cooperação entre sistemas e serviços de saúde em linha de fronteira. In: CONGRÈS DE L'ALASS, 22., 2011, Lausanne. Atas... Barcelona: ALASS, 2011.

SENNA, M. de C. M. et al. O Programa Bolsa Família no Estado do Rio de Janeiro: análise de experiências municipais. In: SEMINÁRIO DE POLÍTICA SOCIAL NO MERCOSUL, 4., 2013, Pelotas. Anais... Pelotas: UCPel, 2013.

\section{Notas}

1 Parte deste artigo foi publicada no VIII Congreso Internacional en Gobierno, Administración y Políticas Públicas: “Gobernando el futuro: Iberoamérica en la cncrucijada". Madri, Espanha, 25 a 28 de setembro de 2017 (NOGUEIRA et al., 2017).

2 Pesquisa "Pactos, Protocolos e o Protagonismo dos Atores Políticos Locais: impasses e condicionantes para o acesso aos bens e serviços na linha de fronteira Arco Sul," desenvolvida, em 2014-2016, teve o apoio e financiamento do Conselho Nacional de Desenvolvimento Científico e Tecnológico (CNPq) (NOGUEIRA, 2017).

3 Adotou-se a referência da Comissão Econômica para a América Latina e o Caribe (CEPAL) sobre institucionalidade social das políticas de proteção social, pois favorecem uma apreensão de maior abrangência sobre o tema (COMISSÃO ECONÔMICA PARA A AMÉRICA LATINA E O CARIBE, 2016).

4 A expressão tratado foi escolhida pela Convenção de Viena sobre o Direito dos Tratados de 1969, como termo para designar, genericamente, um Acordo internacional. O termo Convenção tem o mesmo nível de formalidade do tratado e é mais utilizado para atos multilaterais decorrentes de Conferências Internacionais. Acordo é uma expressão similar a tratado e toma o nome de ajuste ou acordo complementar quando o ato dá execução a outro, anterior, devidamente concluído (ATOS..., 2012).

5 A nova Lei brasileira de migração (Lei ${ }^{\circ}{ }^{13.445}$ ), sancionada em 24 de maio de 2017, influenciará sobremaneira toda política de saúde nas fronteiras do Brasil (BRASIL, 2017).

6 Fronteira MERCOSUL: um estudo sobre o direito à saúde (NOGUEIRA, 2005), A institucionalidade dos sistemas locais de saúde na linha da fronteira MERCOSUL (NOGUEIRA, 2006), O direito à saúde na perspectiva da população residente na linha da fronteira MERCOSUL (NOGUEIRA, 2008), A implementação do Programa SIS FRONTEIRAS e do Pacto pela Saúde-perspectivas para a ampliação do direito à saúde aos usuários estrangeiros na Fronteira Arco Sul (NOGUEIRA, 2011b), Ampliando o direito à saúde - experiências de cooperação entre sistemas elou serviços de saúde em linha de fronteira (NOGUEIRA, 2011a), Uma questão e duas temporalidades: direito à saúde na fronteira MERCOSUL (NOGUEIRA, 2015).

7 População que vive na faixa de fronteira e transita de um país ao outro cotidianamente.

8 Os brasiguaios, brasileiros que migraram na década de 1960 para o Paraguai em busca de melhores condições de trabalho e vida. Por força da legislação brasileira, que outorga a cidadania brasileira aos que residem no País, os brasiguaios não são atendidos no Brasil, e no Paraguai não são atendidos sob a alegação que são brasileiros. Vivem, portanto, em uma situação de irregularidade civil situando-seà margem dos sistemas de proteção social de ambos os países. A estimativa é de 400.000 brasiguaios residindo na faixa de fronteira do Paraguai (NOGUEIRA, 2011a, 2011b).

9 Parte-se do suposto que em formações sociais capitalista a função do Estado nacional é a de favorecer os processos contínuos de acumulação do capital, utilizando as políticas públicas como uma das estratégias atuais de poder. Entretanto, para garantir sua funcionalidade, mantém uma aparente autonomia em relação às demais instituições sociais, obscurecendo o confronto na definição de suas políticas, tanto no aspecto do financiamento como sua regulação jurídico-administrativa.

10 Para Haesbaert (2004), a concepção de território, além de incorporar a dimensão política, diz respeito também às relações econômicas e culturais, pois está intimamente ligada ao modo como as pessoas utilizam a terra, como elas próprias se organizam no espaço e como elas dão significado ao lugar. Só pode ser devidamente apreendido dentro de uma concepção de multiplicidade, de uma multiterritorialidade. Ou seja, apreender o 
território a partir da imbricação de múltiplas relações de poder, do poder mais material das relações econômico-políticas ao poder mais simbólico das relações de ordem cultural, não sendo possível conceber territórios puros.

11 Os municípios de linha de fronteira, neste trabalho, referem-se àqueles que, em função da posição geográfica, fazem limite com o país vizinho e sua sede se localiza no limite internacional, apresentando conurbação (cidades-gêmeas) (BRASIL, 2010).

12 Os Pactos foram abordados a partir de 2003, por ser a partir deste ano que se intensificam os interesses dos Presidentes dos dois países em fortalecer o MERCOSUL. Encerrou-se a busca em 2011, pois após esta data dificilmente se terá Pactos internalizados.

13 Os Comitês de Fronteira são instâncias determinadas legalmente sob a jurisdição do Ministério de Relações Exteriores dos países e responsáveis para tratar especificamente de questões binacionais.

14 As reuniões foram interrompidas em 2005.

\section{Helenara Silveira Fagundes}

helenarasf@hotmail.com

Doutorado em Serviço Social pela Pontifícia Universidade Católica do Rio Grande do Sul (PUCRS)

Professora do Departamento de Serviço Social e do Programa de Pós-Graduação em Serviço Social da Universidade Federal de Santa Catarina (UFSC)

\section{UFSC}

Campus Universitário Reitor João David Ferreira Lima - Trindade

Florianópolis - Santa Catarina - Brasil

CEP: 88.040-900

\section{Vera Maria Ribeiro Nogueira}

vera.nogueira@pq.cnpq.br

Doutorado em Enfermagem pelo Programa de Pós-Graduação em Enfermagem da Universidade Federal de Santa Catarina (UFSC)

Professora do Programa de Pós-Graduação em Política Social e Direitos Humanos da Universidade Católica de Pelotas (UCPel) e do Programa de Pós-Graduação em Serviço Social da Universidade Federal de Santa Catarina (UFSC)

\section{UCPel}

Rua Gonçalves Chaves, 373

Pelotas - Rio Grande do Sul - Brasil

CEP: $96.015-560$

\section{Ineiva Terezinha Kreutz}

ineivakreutz@gmail.com

Mestrado em Educação Escolar Brasileira pela Universidade Federal de Goiás (UFG)

Professora do Curso de Serviço Social da Universidade Estadual do Oeste do Paraná (UNIOESTE)

\section{UNIOESTE - Campus de Toledo}

Rua da Faculdade, 645 - Jardim Santa Maria

Toledo - Paraná - Brasil

CEP: $85.903-000$

\section{Daniela Castamann}

danideon15@gmail.com

Mestrado em Serviço Social pelo Programa de Pós-Graduação em Serviço Social e Política Social da Universidade Estadual de Londrina (UEL)

Professora Assistente do Curso de Serviço Social da Universidade Estadual do Paraná (UNESPAR) 
UNESPAR - Campus Apucarana

Avenida Minas Gerais, 5021 - Vila Nova

Apucarana - Paraná - Brasil

CEP: $86.813-250$

\section{Agência financiadora}

Esta pesquisa foi financiada pelo Conselho Nacional de Desenvolvimento Científico e Tecnológico (CNPq). Protocolo: 8535476623543274. Processo: 47060/2014-3.

Período de vigência: 16/12/2014 a 31/12/2016.

\section{Contribuições dos autores}

Helenara Silveira Fagundes concebeu o artigo e construiu a redação inicial e final, Vera Maria Ribeiro Nogueira colaborou na análise e redação final do artigo, Daniela Castamann colaborou na redação inicial, análise e revisão das referências e Ineiva Terezinha Kreuz colaborou na análise, revisão das referências e formatação.

\author{
Aprovação por Comitê de Ética e consentimento para parti- \\ cipação \\ Não se aplica. \\ Consentimento para publicação \\ Não se aplica.

\section{Conflito de interesses} \\ Não há conflito de interesses.
}

